\title{
Strain-Rate Dependency of Shear Strength for A Highly Overconsolidated Clay
}

\author{
Jian Han $^{1}$, Christophe Dano ${ }^{1}$, Pierre-Yves Hicher ${ }^{1}$ and Zhen-Yu Yin ${ }^{1,2}$ \\ ${ }^{1}$ LUNAM University, Ecole Centrale de Nantes, GeM UMR CNRS 6183, Nantes \\ 44321, France; email: jian.han@ec-nantes.fr; christophe.dano@ec-nantes.fr; pierre- \\ yves.hicher@ec-nantes.fr. \\ ${ }^{2}$ Department of Civil Engineering, Shanghai Jiao Tong University, Shanghai 200240, \\ China; email: zhenyu.yin@gmail.com.
}

\begin{abstract}
The paper summarizes the results from undrained triaxial compression tests on Merville clay, a highly overconsolidated clay at Merville in the north of France. The specimens were prepared in four different overconsolidation ratios $(\mathrm{OCR}=7,14,28,56)$, and for each OCR, undrained shear tests were performed using three or four axial strain rates varying from $0.26 \% / \mathrm{h}$ to $25.89 \% / \mathrm{h}$. The strain-rate dependency of the undrained stress level $q / q_{\mathrm{f}}$, the pore pressure, the effective stress path and the stress ratio $q / p^{\prime}$ were investigated. The undrained shear strength was found to increase with the strain rate. The shear band formation during loading was observed for all strain rates. For each OCR test series, a linear relationship between the normalized peak deviatoric stress and the strain rate was obtained in the semilogarithm plane. As OCR increasing, the slope of best-fitting line for the linear relationship increases. Therefore, the strain rate influence on the normalized undrained shear strength is greater for higher OCRs.
\end{abstract}

\section{INTRODUCTION}

The effect of strain rate on mechanical properties of soils has important engineering implications. In particular, parameters inferred from in situ tests (estimated strain rate $\dot{\varepsilon}_{a}=10^{3}-10^{5} \% / \mathrm{h}$ ) and standard laboratory measurements (conducted at $\dot{\varepsilon}_{a}=0.5-5 \% / \mathrm{h}$ ) must be carefully considered during the selection of design parameters for engineering systems (Yin \& Hicher 2008; Díaz-Rodríguez et al. 2009).

Various studies reported in the literature show that different soils, for example, sands, weak rocks and soft clays, have different responses to changes in strain rate (Casagrande \& Wilson 1951; Lo \& Morin 1972; Lefebvre \& LeBoeuf 1987). Some comprehensive researches on reconstituted clay have been done by Sheahan et al. (1996) and Zhu and Yin (2000), with OCR varying from 1 to 8. Progress in quantifying and understanding undrained strain rate effects requires additional 
comprehensive data on a variety of soil types. There are not many reliable data available on the time-dependent behaviour of stiff clays with different OCRs, particularly natural stiff clays. Some laboratory tests for London clay with different strain rates have been conducted by Sorensen et al. (2007). But the influence of OCR on the strength behaviour was not analyzed.

Thus, this paper focuses on investigating the influence of strain rate and OCR on the strength behaviour of a natural stiff clay.

\section{EXPERIMENTAL PROGRAM}

\section{Description of the clay testedSs}

Merville clay was deposited in the Flanders Region which are now located at the northern France, Belgium and the southeast of England. It was covered by tertiary sedimentation. The soil surface then stood probably about $200 \mathrm{~m}$ above the present surface of the clay. The formations overlying the clay and the top of it were later eroded. This erosion process was sustained to Quaternary era, when Flandrian alluvial soils were deposited on the clay remaining in place which has thus an effective vertical stress much lower than that was applied to the Pliocene. Thus, the clay is known as a stiff, heavily overconsolidated clay (Josseaume 1998). This study deals with the undrained stress-strain behaviour of Merville clay sampled at a depth greater than 3 meters (thickness of the clayey silt layer above the tested clay). Undisturbed samples at a depth of 9-11 m were selected. The clayey specimens have a uniform appearance in the form of a dark gray material. Table 1 shows typical physical properties of the tested clay.

Table 1. Physical Properties of Undisturbed Merville Clay.

\begin{tabular}{ll}
\hline Liquid limit & $97.2 \pm 1 \%$ \\
Plastic limit & $38.6 \pm 1 \%$ \\
Plasticity index (PI) & $58.6 \pm 2 \%$ \\
Natural water content & $32.5 \pm 2.2 \%$ \\
Degree of saturation & $100 \%$ \\
Specific gravity of solids & $2.65 \pm 0.2 \%$ \\
Percent finer than $2 \mu \mathrm{m}$ & $26 \%$ \\
Activity PI $(\%<2 \square \mu \mathrm{m})$ & $2.25 \pm 0.08$ \\
\hline
\end{tabular}

\section{Test program and procedure}

Tests performed in this study include 1D compression test at constant strain rate and isotropically consolidated undrained triaxial compression (denoted CIUC) tests of overconsolidated Merville clay sheared under a constant strain rate. 
1D compression test was done using a Wykeham Farrance testing machine which is a strain controlled machine. The range is 0.00001-9.99999 $\mathrm{mm} / \mathrm{min}$. CIUC tests were carried out using a computer-controlled GDS triaxial testing system.

The specimen for 1D compression test was $70 \mathrm{~mm}$ in diameter and $19 \mathrm{~mm}$ in high. The axial strain rate used in this test was $0.63 \% / \mathrm{h}(0.002 \mathrm{~mm} / \mathrm{min})$. During loading, the drainage was permitted from both sides of the specimen. The strain rate was chosen small enough so that no excess pore pressure was generated during loading.

The specimens for undrained triaxial compression tests were $35 \mathrm{~mm}$ in diameter and $70 \mathrm{~mm}$ in high. Four different axial strain rates were selected: $0.26 \% / \mathrm{h}, 0.52$ $\% / \mathrm{h}, 2.57 \% / \mathrm{h}$ and $25.89 \% / \mathrm{h}$. The $B$ value was checked and found to be greater than 96\%. Specimens were isotropically consolidated at different effective consolidation pressures $(=50 \mathrm{kPa}, 100 \mathrm{kPa}, 200 \mathrm{kPa}$ and $400 \mathrm{kPa}$, respectively) for more than $72 \mathrm{~h}$. After the isotropic consolidation, the cell pressure was held constant, and specimens were sheared to failure at a constant rate of axial strain. The pore pressure was measured at the bottom of the specimen.

When carrying out triaxial tests, we used filter paper strips as side drains which were placed on the lateral surface of each specimen. The purpose was to ensure that the pore water redistribution was completed within a shorter period of time, so that even at a strain rate of $25.89 \% / \mathrm{h}$ the uniformity of the pore pressure within the specimen could be assured.

\section{TEST RESULTS}

\section{One-dimensional compression test}

Fig. 1 shows the result of one-dimensional compression test, giving the void ratio $e$ versus the logarithm of the vertical effective stress $\sigma_{\mathrm{v}}$.

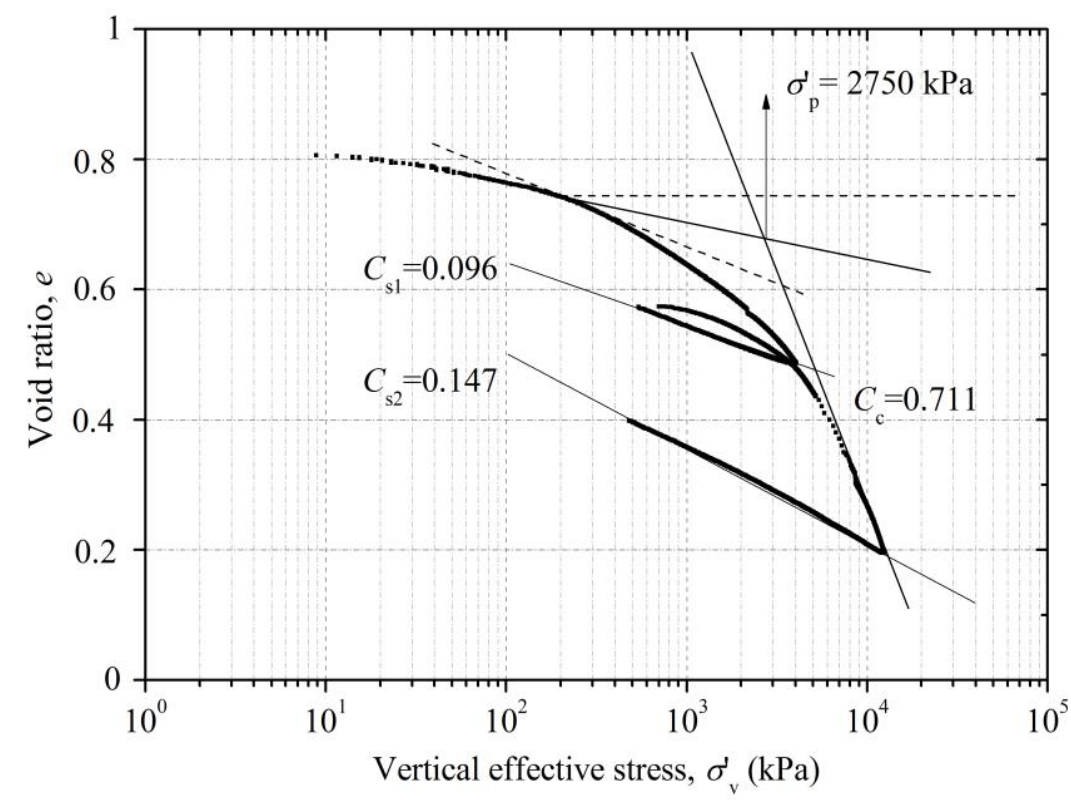

Fig. 1. One-dimensional compression test on Merville clay. 
From Fig. 1, the compression index $C_{\mathrm{c}}$ was measured equal to 0.711 , and the swelling index increases $\left(C_{\mathrm{s} 2}>C_{\mathrm{s} 1}\right)$ as the material is subjected to high stresses due to structural damage.

As mentioned above, the undisturbed samples are from the depth of 9-11 m, which means that the in situ vertical effective stress varied from $100 \mathrm{kPa}$ to $150 \mathrm{kPa}$ because of the variation of ground water table. The preconsolidation pressure obtained from this one-dimensional compression test, following the Casagrande method, is approximately $2750 \mathrm{kPa}$, giving an overconsolidation ratio of more than 18 .

\section{Overview of CIUC tests}

In this study, four series of undrained triaxial compression tests with $\mathrm{OCR}=7,14$, 28 , and 56 were performed. Table 2 presents the results of tests on overconsolidated specimens. It gives the pre-shear consolidation stress condition (effective consolidation pressure $\sigma_{0}$, actual OCR and back pressure $u_{\mathrm{b}}$ ), and stress-strain properties at the peak deviatoric stress (failure) and at maximum excess pore pressure during shearing.

Table 2. Results of CIUC Tests on Stiff Merville Clay.

\begin{tabular}{|c|c|c|c|c|c|c|c|c|}
\hline \multirow{2}{*}{ OCR } & \multirow{2}{*}{$\begin{array}{c}\sigma_{0} \\
(\mathrm{kPa})\end{array}$} & \multirow{2}{*}{$\begin{array}{c}\dot{\varepsilon}_{a} \\
(\% / \mathrm{h})\end{array}$} & \multirow{2}{*}{$\begin{array}{c}u_{\mathrm{b}} \\
(\mathrm{kPa})\end{array}$} & \multicolumn{2}{|c|}{$\begin{array}{l}\text { At maximum excess } \\
\text { pore pressure }\end{array}$} & \multicolumn{3}{|c|}{$\begin{array}{c}\text { At peak deviatoric } \\
\text { stress }\end{array}$} \\
\hline & & & & $\begin{array}{l}\varepsilon_{\text {au }} \\
(\%)\end{array}$ & $\begin{array}{l}\Delta u_{\mathrm{m}} \\
(\mathrm{kPa})\end{array}$ & $\begin{array}{c}\varepsilon_{\mathrm{aq}} \\
(\%)\end{array}$ & $\begin{array}{c}q_{\mathrm{f}} \\
(\mathrm{kPa})\end{array}$ & $\begin{array}{r}\Delta u_{\mathrm{f}} \\
(\mathrm{kPa})\end{array}$ \\
\hline \multicolumn{9}{|c|}{ (a) $\mathrm{OCR}=7$} \\
\hline 6.86 & 401 & 0.26 & 500 & 2.31 & 168 & 2.61 & 631 & 164 \\
\hline 6.88 & 400 & 2.57 & 500 & 2.54 & 168 & 3.14 & 690 & 160 \\
\hline 6.88 & 400 & 25.89 & 500 & 3.06 & 194 & 3.64 & 769 & 185 \\
\hline \multicolumn{9}{|c|}{ (b) $\mathrm{OCR}=14$} \\
\hline 13.82 & 199 & 0.26 & 501 & 2.99 & 117 & 3.49 & 427 & 107 \\
\hline 13.75 & 200 & 2.57 & 500 & 3.09 & 117 & 3.33 & 484 & 116 \\
\hline 13.75 & 200 & 25.89 & 501 & 3.30 & 116 & 3.70 & 532 & 114 \\
\hline \multicolumn{9}{|c|}{ (c) $\mathrm{OCR}=28$} \\
\hline 27.50 & 100 & 0.26 & 700 & 2.37 & 82 & 3.70 & 371 & 65 \\
\hline 27.23 & 101 & 0.52 & 699 & 2.38 & 82 & 3.20 & 387 & 78 \\
\hline 27.23 & 101 & 2.57 & 700 & 2.47 & 89 & 2.96 & 415 & 81 \\
\hline 27.78 & 99 & 25.89 & 701 & 2.61 & 78 & 3.10 & 455 & 74 \\
\hline \multicolumn{9}{|c|}{ (d) $\mathrm{OCR}=56$} \\
\hline 53.92 & 51 & 0.26 & 499 & 1.60 & 41 & 2.92 & 312 & 35 \\
\hline 55.00 & 50 & 2.57 & 500 & 1.55 & 37 & 2.50 & 337 & 34 \\
\hline 56.12 & 49 & 25.89 & 501 & 2.13 & 37 & 2.69 & 383 & 31 \\
\hline
\end{tabular}

Values of interest for comparative study in this paper are presented in Table 2, where $\Delta u_{\mathrm{m}}$ is the maximum excess pore pressure, $\varepsilon_{\mathrm{au}}$ is the axial strain corresponding to $\Delta u_{\mathrm{m}}, q_{\mathrm{f}}$ is the peak deviatoric stress, and $\varepsilon_{\mathrm{aq}}$ and $\Delta u_{\mathrm{f}}$ are the axial strain and excess pore pressure corresponding to $q_{\mathrm{f}}$, respectively. For each test, the axial strain $\varepsilon_{\mathrm{au}}$ is 
less than the $\varepsilon_{\mathrm{aq}}$, which means the maximum excess pore pressure $\Delta u_{\mathrm{m}}$ is reached earlier than the peak shear stress $q_{\mathrm{f}}$.

\section{Tests at $\mathrm{OCR}=7$}

Fig. $2 a$ presents the relationship between stress level and axial strain for the test series with $\mathrm{OCR}=7$. Strain localization and shear band formation were observed within these overconsolidated specimens even at the lowest strain rate. The axial strain corresponding to the peak stress increases with an increase in the strain rate. Fig. $2 b$ presents the relationship between excess pore pressure level and axial strain. The axial strain corresponding to the maximum pore pressure increases with an increase in the strain rate.

The relationship between stress ratio and axial strain is shown in Fig. $2 c$, where $p^{\prime}$ $=\left(\sigma_{1}+2 \sigma_{3}^{\prime}\right) / 3$ is the mean effective stress. These three curves almost coincide during the first stages of the loading and then diverge before the peak of the stress-strain curve. Fig. $2 d$ shows that higher strain rates correspond to larger peak stresses. The best-fitting line for the relationship between the normalized peak stress and the axial strain rate can be represented by a straight line in a semi-logarithmic plane.
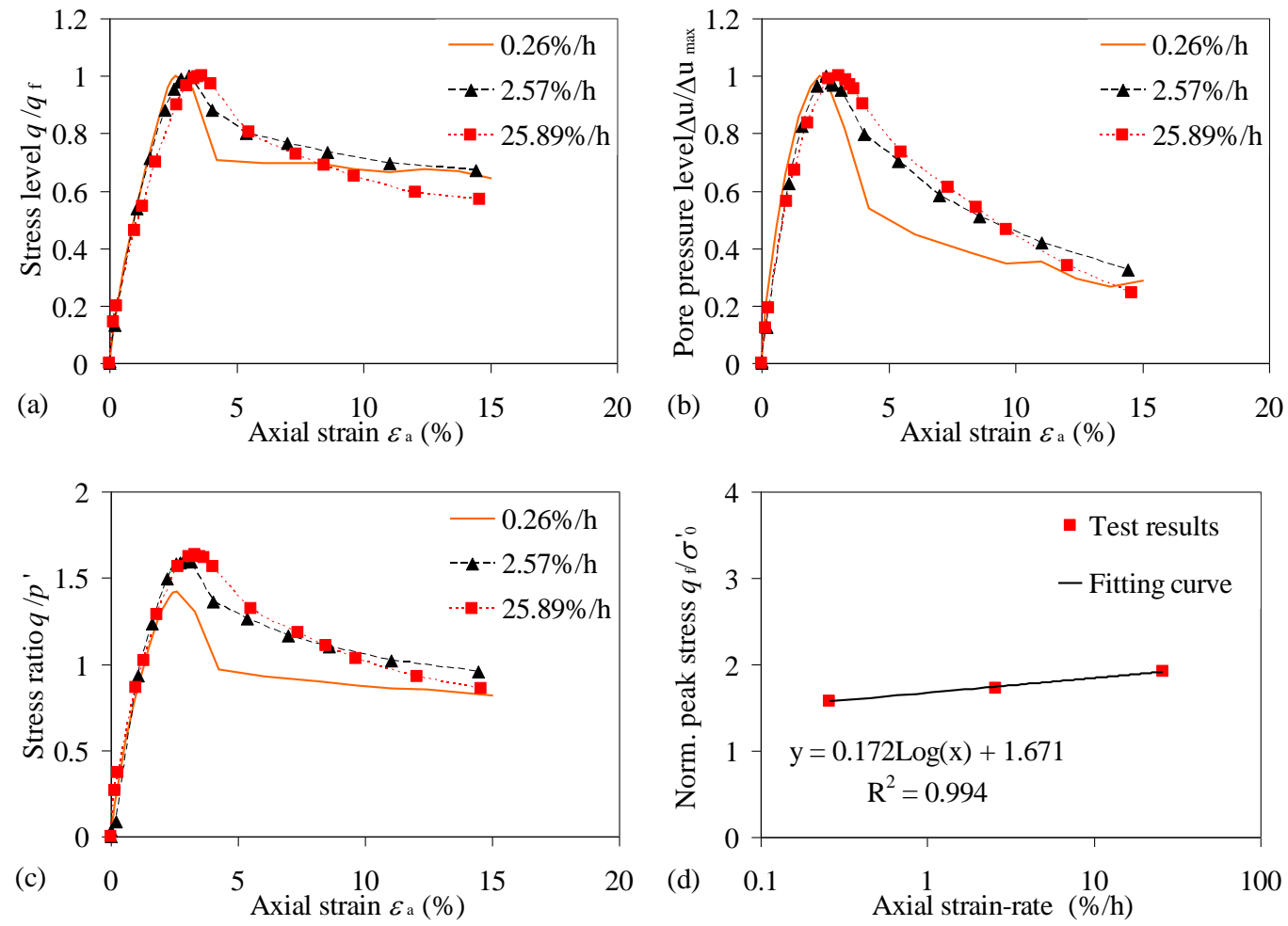

Fig. 2. Tests at $\mathrm{OCR}=7$ : (a) Stress level versus axial strain. (b) Excess pore pressure level versus axial strain. (c) Stress ratio versus axial strain. (d) Normalized peak shear stress versus axial strain rate. 


\section{Tests at $\mathrm{OCR}=14,28$ and 56}

Figs. 3 to 5 present the relationship between stress level and axial strain $(a)$, the relationship between excess pore pressure level and axial strain $(b)$, the relationship between stress ratio and axial strain $(c)$, and the relationship between normalized peak stress and axial strain rate $(d)$ for the test series with $\mathrm{OCR}=14,28$ and 56, respectively. Strain localization and shear band formation were observed in these overconsolidated specimens for the tests at the three strain rates. The values of the axial strain corresponding to the peak stress and the maximum pore pressure are almost equal. Figs. $3 a$ to $5 a$ show that the stress-strain curves are almost identical before reaching the peak stress, which means that the evolution of stress level is almost independent of the strain rate before reaching the peak stress. The same phenomenon is observed in Figs. $3 b$ to $5 b$ for the evolution of the pore pressure.

Figs. $3 d$ to $5 d$ show that higher strain rate leads to higher peak stress. The bestfitting line for the relationship between the normalized peak stress and the axial strain rate can also be represented by a straight line in a semi-log diagram.
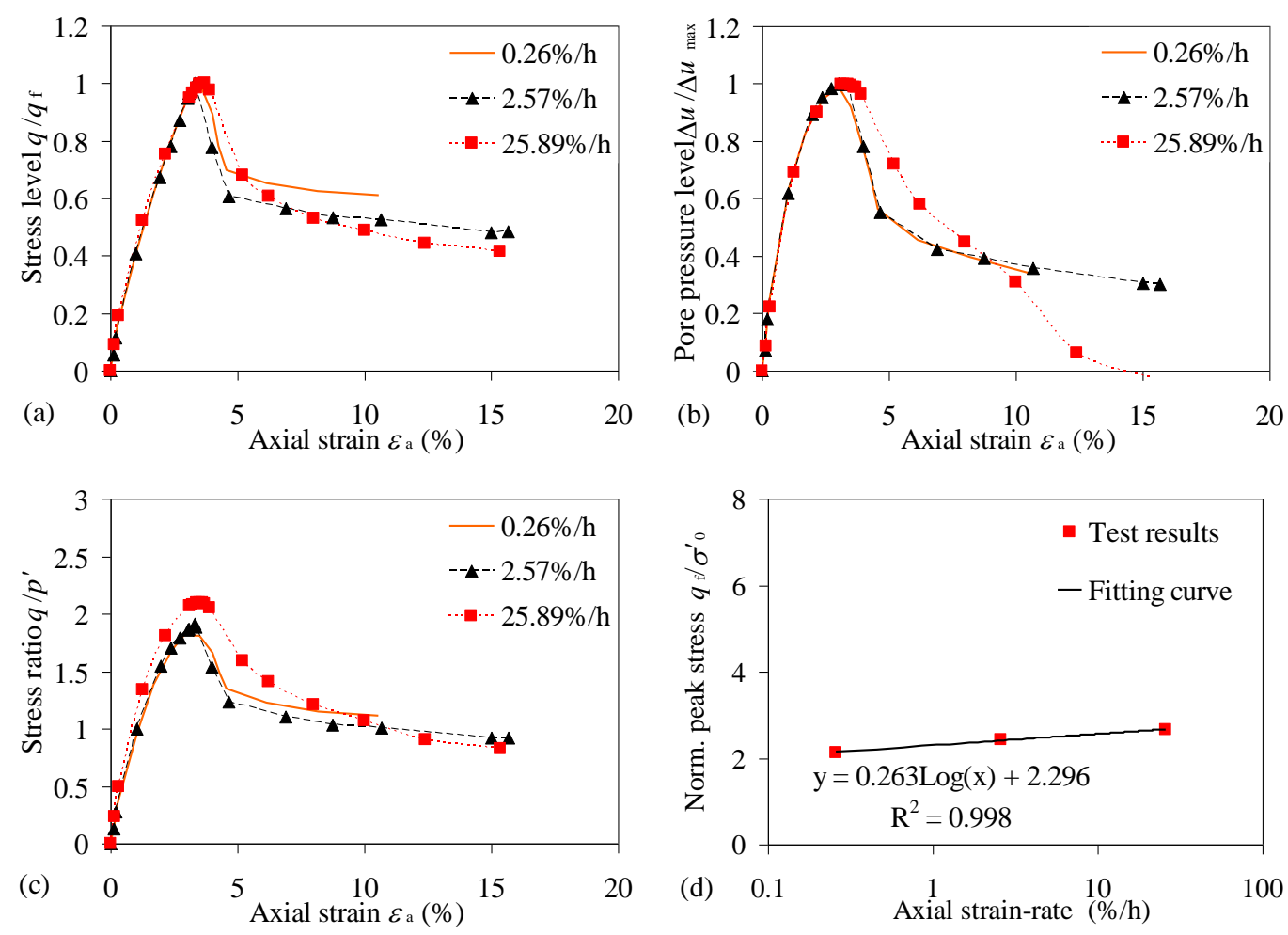

Fig. 3. Tests at $O C R=14$ : (a) Stress level versus axial strain. (b) Excess pore pressure level versus axial strain. (c) Stress ratio versus axial strain. (d) Normalized peak shear stress versus axial strain rate. 

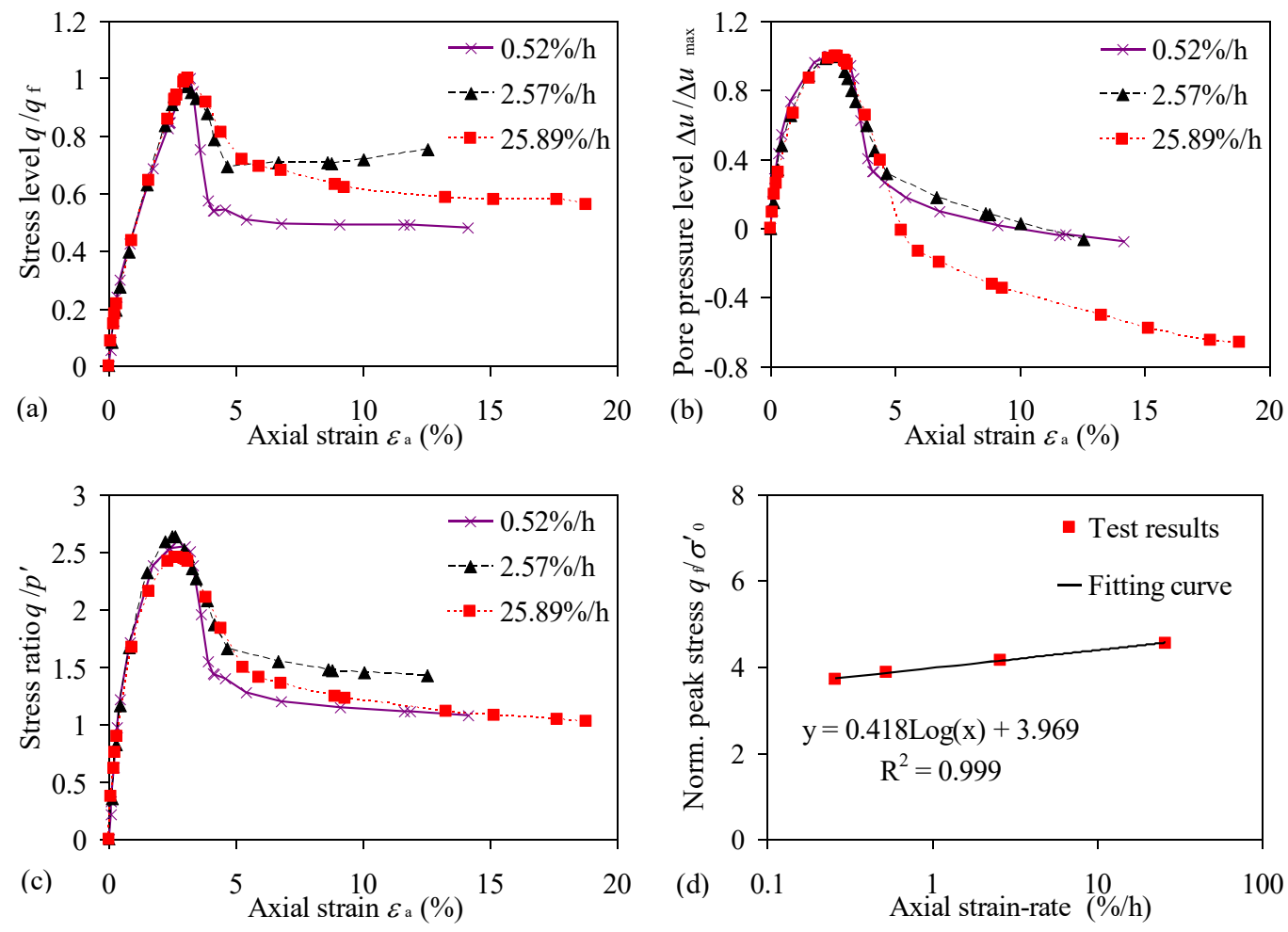

Fig. 4. Tests at $\mathrm{OCR}=28$ : (a) Stress level versus axial strain. (b) Excess pore pressure level versus axial strain. (c) Stress ratio versus axial strain. (d) Normalized peak shear stress versus axial strain rate.

\section{Analysis of the test results}

Fig. $6 a$ presents the effective stress paths at different confining pressures $(50 \mathrm{kPa}$, $100 \mathrm{kPa}, 200 \mathrm{kPa}$ and $400 \mathrm{kPa})$ and at different strain rates $(0.26 \% / \mathrm{h}, 2.57 \% / \mathrm{h}$ and $25.89 \% / \mathrm{h})$. We obtained three parallel failure lines for the three different strain rates (Fig. $6 a$ ). Thus, the apparent friction angle, $\varphi^{\prime}$, appears independent of the strain rate. Its mean value is $24^{\circ}$.

Fig. $6 b$ shows the relationships between the normalized undrained shear strength $\left(q_{\mathrm{f}} / \sigma_{0}\right)$ and the axial strain rate $\left(\dot{\varepsilon}_{a}\right)$ summarized from Fig. $2 d$, Fig. $3 d$, Fig. $4 d$, and Fig. $5 d$. For each OCR, the set of test points is fitted with a straight line in a semi-log diagram, and the equations of these lines are shown in the figure. The slope of each line reflects the rate of the undrained strength increase with the strain rate. To characterize the influence of the strain rate on the shear strength, Zhu \& Yin (2000) suggested that the undrained shear strength varies almost linearly with the logarithm of the strain rate, expressed as follows:

$$
\rho_{q}=\frac{\Delta\left(q_{\mathrm{f}} / \sigma_{0}^{\prime}\right)}{\Delta \log \left(\dot{\varepsilon}_{a}\right)}
$$

where $\rho_{\mathrm{q}}$ is the slope of each straight line shown in Fig. $2 d$, Fig. $3 d$, Fig. $4 d$, and Fig. $5 d$. 

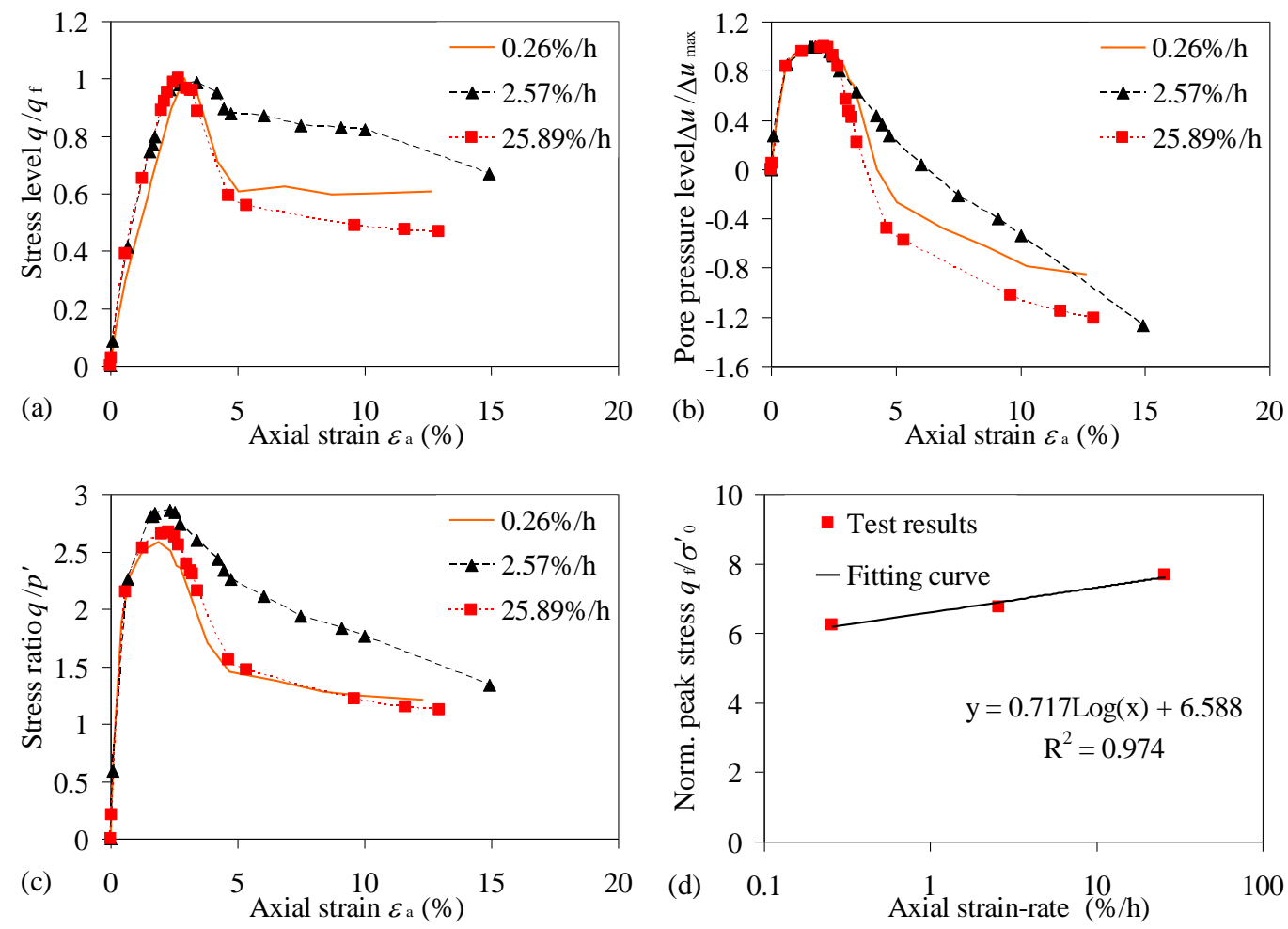

Fig. 5. Tests at $\mathrm{OCR}=56$ : (a) Stress level versus axial strain. (b) Excess pore pressure level versus axial strain. (c) Stress ratio versus axial strain. (d) Normalized peak shear stress versus axial strain rate.

For $\mathrm{OCR}=7,14,28$ and 56, the values of the slopes are $0.172,0.263,0.418$ and 0.717 , respectively.

Fig. $6 c$ shows the relationship between $\rho_{\mathrm{q}}$ and OCR, in which $\rho_{\mathrm{q}}$ appears to increase with an increase in OCR. It can be concluded that for Merville clay the strain rate influence on the normalized undrained shear strength is greater for higher OCRs.

\section{CONCLUSIONS}

A total of thirteen undrained triaxial tests on isotropically consolidated Merville clay with OCR up to 56 were carried out at different axial strain rates. The influence of OCR and strain rate on the undrained shear strength behaviour was studied.

The following conclusions can be drawn from this study:

(1) For undrained triaxial tests, higher strain rate results in higher undrained shear strength for OCRs ranging from 7 to 56 for Merville clay within the strain-rate range tested. Strain localization and shear band formation develop systematically during shearing at any strain rate.

(2) There are three parallel failure lines for the three different strain rates. Thus, the apparent friction angle of Merville clay appears independent of the strain rate. Its mean value is equal to $24^{\circ}$. 
(3) For each OCR test series, the relationship between the normalized peak strength and the axial strain rate can be fitted by a straight line in a semi-logarithmic plot.

(4) For each OCR test series, the value of the strain-rate coefficient, $\rho_{\mathrm{q}}$, calculated from Eq.(1) was determined by the slope of the fitting line shown in Fig. $6 b$. The value of $\rho_{\mathrm{q}}$ increases with OCR increasing. Hence, it can be concluded that for Merville clay the strain rate influence on the normalized undrained shear strength is more pronounced for higher OCRs.

Further experiments will be carried out on reconstituted samples, in order to obtain a better understanding of the strain-rate effect and the influence of OCR in intact and reconstituted samples of Merville clay.
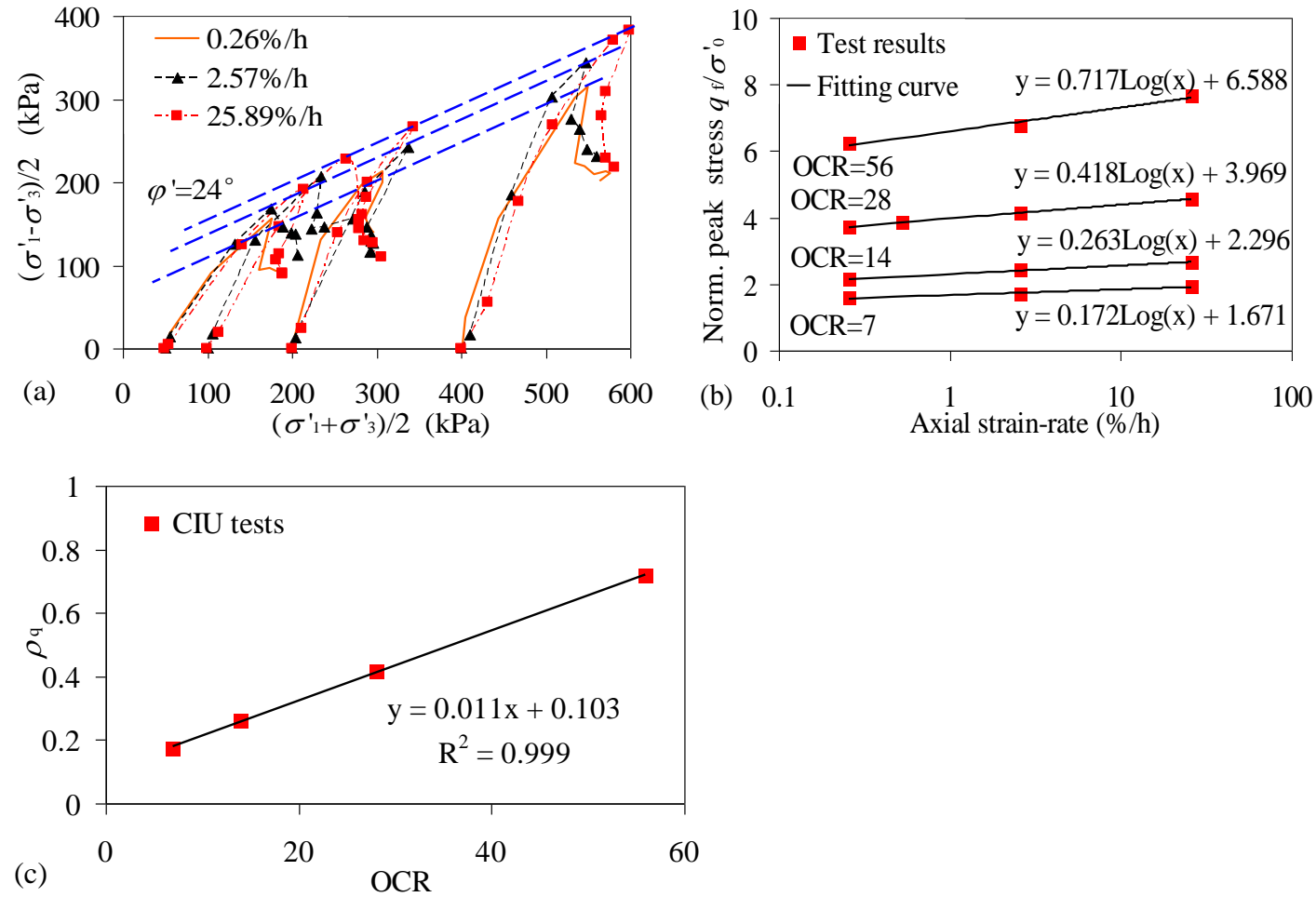

Fig. 6. (a) Undrained effective stress paths at different strain rates. (b) Relationship between normalized peak shear stress and axial strain rate. (c) Relationship between $\rho_{\mathrm{q}}$ and OCR.

\section{ACKNOWLEDGMENTS}

This research was financially supported by China Scholarship Council (CSC), the ANR project SOLCYP. These supports are greatly appreciated.

\section{REFERENCES}


Bjerrum, L. (1973). "Problems of soil mechanics and construction on soft clays and structurally unstable soils." Proc. 8th Intl. Conference on Soil Mechanics and Foundation Engrg., Moscow, 3: 111-159.

Casagrande, A. and Wilson, S.D. (1951). "Effect of rate of loading on the strength on clays and shales at constant water content." Géotechnique. 2(3): 251-263.

Díaz-Rodríguez, J.A., Martínez-Vasquez, J.J. and Santamarina, J.C. (2009). "Strainrate effects in Mexico city soil." J. Geotechnical and Geoenvironmental Engrg. 135(2): 300-305.

Graham, J., Crooks, J.H.A. and Bell, A.L. (1983). "Time effects on the stress-strain behaviour of natural soft clays." Géotechnique. 33(3): 327-340.

Josseaume, H. (1998). "Engineering properties of the Flanders clay at Dunkerque and Calais." Revue Française de Géotechnique. 84: 3-26.

Lo, K.Y., and Morin, J.P. (1972). "Strength anisotropy and time effects of two sensitive clays." Canadian Geotech. J. 9: 261-277.

Lefebvre, G. and LeBoeuf, D. (1987). "Rate effects and cyclic loading of sensitive clays." J. Geotech. Engrg., ASCE, 113(5): 476-489.

Sheahan, T.C., Ladd, C.C. and Germaine, J.T. (1996). "Rate-dependent undrained shear behavior of saturated clay." J. Geotech. Engrg., ASCE, 122(2): 99-108.

Sorensen, K.K., Baudet, B.A. and Simpson, B. (2007). "Influence of structure on the time-dependent behaviour of a stiff sedimentary clay." Géotechnique. 57(1): 113124.

Yin, Z.Y. and Hicher, P.Y. (2008). "Identifying parameters controlling soil delayed behaviour from laboratory and in situ pressuremeter testing." Intl. J. Numer. Anal. Methods Geomech. 32(12): 1515-1535.

Zhu, J.G. and Yin, J.H. (2000). "Strain-rate-dependent stress-strain behavior of overconsolidated Hong Kong marine clay." Canadian Geotech. J. 37: 1272-1282. 